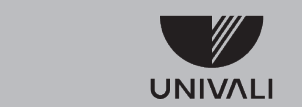

UNIVERSIDADE DO VALE DO ITAJAí

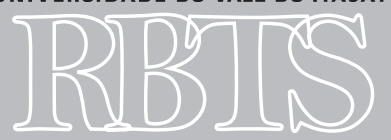

Revista Brasileira de Tecnologias Sociais
Professora pesquisadora do Programa de Mestrado em Saúde da Universidade do Vale do Itajaí (UNIVALI), Itajaí-SC. Doutora em Enfermagem pela Universidade Federal de Santa Catarina (UFSC). E-mail: jusandri@univali.br

${ }^{2}$ Acadêmica do $8^{\circ}$ período do Curso de Graduação em Enfermagem da Universidade do Vale do Itajaí. E-mail: becker2923@gmail.com

${ }^{2}$ Acadêmica do $9^{\circ}$ período do Curso de Graduação em Enfermagem da Universidade do Vale do Itajaí. E-mail: karol.gava@hotmail.com

2 Acadêmica do $10^{\circ}$ período do Curso de Graduação em Enfermagem da Universidade do Vale do Itajaí. E-mail: rafaellarebello@gmail.com

\section{CARACTERIZAÇÃO DAS AÇỔES DE EDUCAÇÃO PERMANENTE EM SAÚDE NO ESTADO DE SANTA CATARINA}

\section{CHARACTERIZATION OF ACTIONS OF CONTINUING EDUCATION IN HEALTH IN THE STATE OF SANTA CATARINA}

\author{
SANDRI, Juliana Vieira de Araujo'; BECKER, Gisele²; GAVA, \\ KAROLINE $^{2}$;REBELLO, RAFAELLA ${ }^{2}$
}

Resumo:Este artigo objetiva caracterizar as ações da Educação Permanente em Saúde (EPS) no Estado de Santa Catarina no contexto da força do trabalho vivo do Sistema Único de Saúde. Estudo com análise quantitativa com os participantes e articuladores das Comissões de Integração Ensino e Serviço Regionais (CIES). No Estado há 16 CIES e elas estão distribuídas por regiões descentralizadas, sendo que cada uma delas está subordinada a uma Comissão de Intergestores Regionais (CIR), conforme determina a Portaria GM/MS1996 de 2003. Participaram da pesquisa as CIES que tiveram ações de EP no período de 2011 a 2013, perfazendo um total de 14 CIES. Todas foram identificadas pela região correspondente $(\mathbf{R})$. Como técnica para a coleta de dados utilizou-se o questionário para a obtenção do perfil das ações de educação permanente e a entrevista para apresentar a articulação do quadrilátero (gestão, ensino, serviço e controle social) na condução da Política de Educação Permanente em Saúde em Santa Catarina. Os resultados indicam que as regiões $\mathbf{R} 7, \mathbf{R} \mathbf{9}$ e $\mathbf{R} \mathbf{2}$ apresentaram o maior número de ações realizadas no período (47,6\%); em relação à carga horária das ações $\mathbf{R} 7, \mathbf{R} 9$ e $\mathbf{R} 5$ se sobressaem (88,7\%); R2, $\mathbf{R} 3$ e $\mathbf{R} 7$ foram as regiões de maior expressão quanto ao quantitativo de participantes (61\%); $\mathbf{R} 7$, assim, destaca-se como uma região expressiva no número de ações, carga horária e quantitativo de participantes; as ações de EPS foram direcionadas para o serviço $(47,6 \%)$, gestão $(32,1 \%)$, ensino $(16,7 \%)$ e controle social (03,6\%); a categoria profissional que mais esteve presente foi enfermeiro (13\%), seguida pelo odontólogo (10,8\%). Muito se tem que avançar, contudo se pode deduzir que o Estado de Santa Catarina está cumprindo o seu papel quando realiza a articulação dessa política por meio da CIES Estadual e quando estimula a autonomia 
das CIES Regionais na condução da sua operacionalidade. Somos um eterno aprendiz deste SUS que não para de crescer e de se consolidar como a maior proteção social que um cidadão pode almejar.

Palavras-chave: Educação Permanente. Sistema Único de Saúde. Recursos humanos em saúde.

Abstract: This paper characterizes the actions of Continuing Education in Health $(\mathrm{CEH})$ in the state of Santa Catarina, in the context of the labor force of the Unified Health System. The study consists of a quantitative analysis with the participants and organizers of the Committees of Educational Integration and Regional Services (CIES). The state has 16 CIES, distributed by decentralized regions. Each one is subordinate to a Committee of Regional Inter-managers (CIR), as determined by GM/MS1996 of 2003. The CIES that had actions in Continuing Education in 2011-2013 took part in the research, with a total of 14 participating CIES. All were identified by the corresponding region $(\mathrm{R})$. For the data collection, a questionnaire was used to obtain the profile of continuing education actions, with interviews to present the four facets (management, teaching, service and social control) of the implementation of the Policy of Continuing Education in Health in Santa Catarina. The results indicate that regions R7, R9 and $\mathrm{R} 2$ had the highest number of actions in the period (47.6\%); in terms of the workload of the actions, R7, R9 and R5 stood out (88.7\%); R2, R3 and R7 were the regions with the highest number of participants (61\%); $\mathrm{R} 7$ also stood out as a region with a significant number of actions, workload and number of participants; the actions of CEH were focused on the service (47.6\%), management (32.1\%), education (16.7\%) and social control (03,6\%); the occupational category that was most represented was the nurse (13\%), followed by the dentist (10.8\%). There is much room for improvement, but we can deduce that the State of Santa Catarina is fulfilling its role in articulating this policy through the State CIES, and promoting the autonomy of the regional CIES in conducting its operations. We are an eternal apprentice of this SUS (Brazilian national health system), which continues to grow and consolidate itself as the greatest social protection any citizen could wish for.

Keywords: Continuing Education. Unified Health System. Health Manpower.

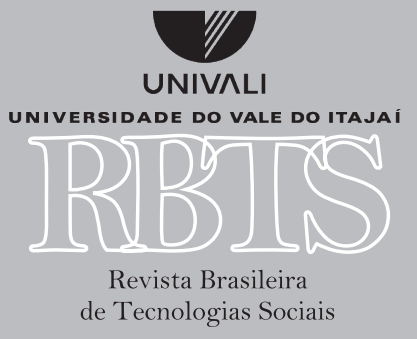

Revista Brasileira de Tecnologias Sociai 
A Portaria no 1.996/07 prevê, no Art. $2^{\circ}$, que a condução regional da Política Nacional de Educação Permanente em Saúde (PNEPS) ocorre por meio das Comissões Intergestores Regionais (CIR), com a participação das Comissões de Integração Ensino-Serviço (CIES), definidas como instâncias intersetoriais e interinstitucionais permanentes que participam da formulação e do desenvolvimento da PNEPS. Esta tem o propósito de promover mudanças no modelo de formação do SUS, discutir a integralidade da atenção à saúde e favorecer a articulação intersetorial por meio das necessidades dos usuários; contribuir com a formação para o SUS, considerando os novos desenhos organizativos da gestão (BRASIL, 2007).

Frente à fragilidade da formação do profissional da saúde e das reais necessidades no cotidiano do trabalho, a SGTES/MS assume o papel de gestor federal do SUS no que diz respeito à legislação e à ordenação da formação e do desenvolvimento de pessoal para o setor. Sendo assim, em 13 de fevereiro de 2004, por meio da Portaria GM/MS n ${ }^{\circ}$ 198, institui a PNEPS como estratégia do SUS para a formação e para o desenvolvimento de trabalhadores para o setor (BRASIL, 2004a; 2004b).

A Portaria GM//MS n 198 (BRASIL, 2004a) foi alterada pela Portaria GM/MS n 1.996 em 20 de agosto de 2007 (BRASIL, 2007), estabelecendo novas diretrizes e estratégias para a implementação da PNEPS. Essa Portaria reafirma os princípios da EPS como norteadores para a construção dos planos regionais de EPS e das ações educativas na saúde. Também recoloca a questão de que as demandas para a formação devem considerar, prioritariamente, os problemas cotidianos referentes à atenção à saúde e à organização do trabalho. Além disso, institui que as ações de educação na saúde passam a compor o Pacto de Gestão do Pacto pela Saúde.

O Pacto da Saúde está pautado na Portaria GM/MS n 399, de 22 de fevereiro de 2006, e contempla três componentes que visam à promoção, à transformação e ao fortalecimento do SUS. São eles: a) Pacto pela Vida, composto por um contíguo de prioridades no âmbito sanitarista; b) Pacto em Defesa do SUS, com o objetivo de debater o sistema segundo seus princípios; e c) Pacto de Gestão do SUS, cujas suas diretrizes referenciam-se à "regionalização, ao financiamento, ao planejamento, à programação pactuada e integrada à saúde, à regulação da atenção à saúde e da assistência, à participação e controle social, à gestão do trabalho e à educação na saúde” (BRASIL, 2006).

A PNEPS no Estado de Santa Catarina (SC) tem sua história marcada por idas e vindas nos distintos cenários em que essa política se estruturou desde sua implantação em 2003 e, desde 2007, procura se adequar às novas diretrizes da PNEPS. Cabe destacar que em todos os momentos, independente da operacionalidade ou das denominações que tenham sido designadas, seja por meio da Portaria 198/04 ou pela Portaria 1.996/07, sem dúvida essa estratégia do SUS contribuiu para a formação de trabalhadores, gestores e usuários, mas, sobretudo, para a organização de novos desenhos assistenciais nos diferentes cenários do SUS.

Justifica-se a importância da pesquisa, visto que em tempos atuais a qualidade do cuidado à saúde em todos os níveis de atenção tem ocupado espaço na agenda da gestão municipal como imagem-objetivo prioritária para a consolidação do SUS. Por fim, esse produto assume importância quando novas concepções didático-pedagógicas são exigidas para a formação, a capacitação, a qualificação e para o aperfeiçoamento pessoal, profissional e institucional, de maneira que o trabalhador do SUS não seja dominado imperiosamente pela dimensão instrumental, mas que seja capaz de construir a crítica a partir da sua própria prática, pois, além de saber fazer, o trabalhador 
precisa saber pensar a produção clínica e social da saúde à luz dos determinantes e das dimensões inerentes, a fim de garantir uma melhor assistência ao usuário do SUS.

Assim, um grande desafio que se apresenta em SC é a falta de um "mapa estadual” que mostre as ações de EPS. Desta forma, surgem os questionamentos: Que ações de EPS são desenvolvidas em Santa Catarina?

Esta proposta faz parte do programa de pesquisa do Grupo de Pesquisa ARGOS Educação na Saúde e Gestão do Trabalho, vinculado ao Mestrado Profissional em Saúde e Gestão do Trabalho, o qual tem como preocupações centrais a educação em saúde, incluindo a formação e a qualificação profissional, a gestão do trabalho em saúde e as tecnologias de promoção da saúde. Este estudo teve o financiamento do Programa Institucional de Bolsas de Iniciação Científica PIBIC/CNPq, por meio do Edital 03/2013.

\section{Metodologia}

O estudo consiste em uma análise quantitativa, cujos participantes foram representantes das 16 CIES que estivessem condizentes com os critérios de inclusão: ter organizado e realizado ações de EPS (2011-2013) e aceitar participar da pesquisa.

Para análise, foi identificada a caracterização das ações de EP realizadas em SC concernente a: temática; frequência; CIES regional envolvida; carga horária; participantes (quantidade e categoria profissional) e instituições envolvidas. No procedimento analítico, construiu-se uma planilha do Excel para auxiliar na análise estatística descritiva e inferencial, as quais estão apresentadas em quadros e tabelas.

A coleta e a análise dos dados ocorreram no primeiro semestre de 2014, durante os encontros estaduais de reuniões ordinárias da CIES Estadual e eventos que congregaram os articuladores regionais, como meio de divulgação da pesquisa e primeiro contato com os participantes, os quais, após aceitarem participar, enviaram por e-mail os dados solicitados e outros foram entrevistados neste espaço.

As dimensões éticas seguiram a Resolução 466/12/CNS, quais sejam: Foi solicitada a “carta de anuência” à instância gerencial em nível estadual responsável pela Política Nacional de Educação Permanente (Diretoria de Educação Permanente em Saúde - DEPS/SES). Foram realizadas a entrega e a leitura do Termo de Consentimento Livre e Esclarecido (TCLE). O projeto está aprovado pelo CEP/UNIVALI com o parecer n. 34827 em 25/ 05/ 2012.

O anonimato e a confidencialidade das informações estão respeitados. As CIES foram identificadas pela letra $\mathbf{R}$, acrescidas de um número em ordem crescente, distribuído da macrorregião oeste para leste, sendo que as regiões $\mathbf{R} 13$ e $\mathbf{R} \mathbf{1 4}$ não foram contempladas no estudo pela recusa na participação e/ou por não estarem dentro dos critérios de inclusão. As regiões R1 1, R12, R15 e R16 não foram consideradas na parte quantitativa por falta de dados.

Foi assegurado que as informações coletadas estão sendo utilizadas, exclusivamente, para fins da pesquisa. Caso haja manifestações de interesse, comprometeu-se apresentar, na forma oral, os resultados encontrados às diferentes instâncias gestoras em âmbito estadual (CES, COSEMS, CIB e CIES Estadual). Cabe ressaltar que os resultados serão socializados na comunidade científica, por meio da apresentação e da publicação do trabalho em eventos nacionais, além da 
publicação de artigos em periódicos científicos de circulação nacional. Assim, acredita-se que se estará colaborando para a difusão do conhecimento de modo a contribuir com o debate em torno desta importante temática, sendo que se está ciente e se comprometeu apresentar os devidos agradecimentos à fonte de financiamento da pesquisa.

Figura 01- Distribuição das CIES em Santa Catarina, 2014

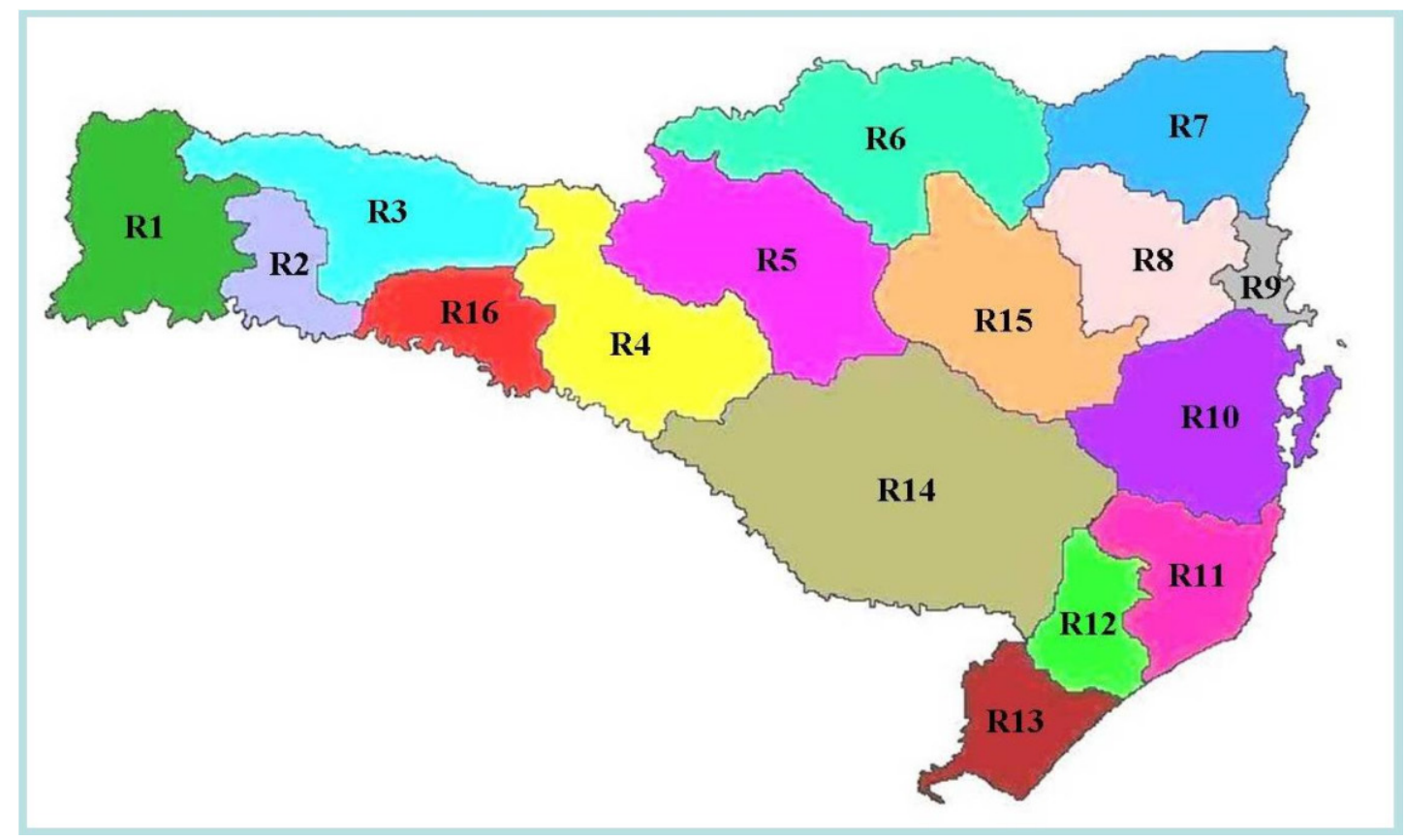

Fonte: Instrumento de Pesquisa PIBIC, 2014.

\section{Resultados E DisCuSSÃo}

As CIES em Santa Catarina são distribuídas por regiões descentralizadas a fim de que os gestores municipais tenham maior autonomia na elaboração de políticas voltadas às necessidades específicas locais. O princípio da descentralização, adotado desde a década de 90, tem a finalidade de auxiliar a distribuição de recursos entre as unidades federativas, visando ao mais correto financiamento das ações e dos serviços de saúde. A Portaria GM/MS nº 1.996/07, em consonância com a PNEPS, que incide intermediária à CIR e CIES, define as transferências de recursos para EPS vindas do Fundo Nacional de Saúde para os respectivos Fundos Estaduais ou Municipais de Saúde às regiões aderentes ao Pacto de Gestão (FERRAZ et al, 2013).

Em 2009, a Comissão Intergestores Bipartite (CIB) decidiu pela formação de 16 CIR, com 16 CIES, abrangendo as macrorregiões de saúde e todas as cidades do Estado, atendendo ao Plano Diretor de Regionalização (PDR) 2008 e à Portaria n 1.996/07 (CIB/SES-SC, 2007a, 2007b, 2009). Em 2010, foi instituída a Comissão Estadual de EPS em SC, como uma câmara técnica da CIB responsável pelas ações relativas à EPS, contidas no Plano Estadual de Educação Permanente em Saúde (PEEPS).

Nesse cenário dinâmico em que a saúde está inserida, encontra-se a educação permanente em saúde (EPS), que volta seu olhar para os processos de trabalho e para a importância do trabalho vivo que dá significado ao trabalho em ato, que se produz no momento 
de sua atividade, cujos usuários e trabalhadores se encontram para a produção do cuidado. A EPS pode ser considerada uma ferramenta estratégica de aproximação do ato de cuidar, possibilitando a troca de saberes e experiências entre o saber teórico e prático (MERHY; FEUERWERKER; CECCIM, 2006). Saupe, Cutolo e Sandri (2008, p. 449) propõem um conceito ampliado de educação permanente:

Direito de cidadania que inclui a produção, incorporação, reelaboração, aplicação e testagem de conhecimentos, habilidades, atitudes e tecnologias, através de um processo multidimensional de perspectivas e prioridades, efetivado na relação dialógica e participativa entre os diferentes saberes dos sujeitos sociais, negociada entre as partes envolvidas no processo de ensino e aprendizagem, desenvolvida a partir de projetos de curta, média longa duração, promovendo a valorização da subjetividade, a cooperação, a solidariedade, a troca, a superação da realidade existente, para construção da realidade almejada e possível. Os espaços de interação desta educação incluem a vida cotidiana, a educação formal e informal, o preparo para o trabalho, a organização e controle social, a cultura e o lazer.

Neste sentido, a Política Nacional de Educação Permanente em Saúde, na sua operacionalidade, é criada com objetivos de reduzir este hiato, permitindo aproximações entre o Núcleo Formador e o Núcleo de Trabalho com vistas à construção e à consolidação do bem maior do Movimento pela Reforma Sanitária Brasileira, que é o SUS. Outros recortes são possíveis nas tentativas de se formar profissionais de saúde comprometidos com os princípios e as doutrinas do SUS como as Diretrizes Curriculares Nacionais, o Pró-Saúde, Pet-Saúde, os Mestrados Profissionais em Saúde, as Residências Multiprofissionais de Saúde da Família, todos preocupados com os processos formativos não vinculados diretamente ao processo de trabalho.

As CIES preocupam-se em sua essência com os processos de trabalho, suas demandas, necessidades, características, ou seja, com a realidade material que se dá a assistência à saúde. A Tabela 01 mostra a distribuição de ações de educação permanente em saúde associada ao quantitativo de carga horaria e de participantes por CIES, nominada pela letra $\mathbf{R}$.

Tabela 01- Distribuição da quantidade de ações de EPS realizadas- SC (2011-2013), 2014

\begin{tabular}{lcccccc}
\hline CIES & \multicolumn{2}{c}{ Ações } & \multicolumn{2}{c}{ Carga Horária } & \multicolumn{2}{c}{ Participantes } \\
& $\mathrm{N}$ & $\%$ & $\mathrm{~N}$ & $\%$ & $\mathrm{~N}$ & $\%$ \\
\hline R1 & 05 & 06,0 & 200 & 01,6 & 640 & 06,0 \\
R2 & 11 & 13,1 & 204 & 01,7 & 3412 & 32,3 \\
R3 & 09 & 10,7 & 392 & 03,2 & 998 & 09,4 \\
R4 & 08 & 09,5 & 180 & 01,5 & 783 & 07,4 \\
R5 & 04 & 04,8 & 1568 & 12,8 & 483 & 04,6 \\
R6 & 05 & 06,6 & 88 & 00,7 & 296 & 02,8 \\
R7 & 16 & 19,0 & 5108 & 41,8 & 2034 & 19,3 \\
R8 & 06 & 07,1 & 40 & 00,3 & 120 & 01,1 \\
R9 & 13 & 15,5 & 4165 & 34,1 & 944 & 08,9 \\
R10 & 07 & 08,3 & 274 & 02,3 & 864 & 08,2 \\
\hline Total & $\mathbf{8 4}$ & $\mathbf{1 0 0 , 0}$ & $\mathbf{1 2 . 2 1 9}$ & $\mathbf{1 0 0 , 0}$ & $\mathbf{1 0 . 5 7 4}$ & $\mathbf{1 0 0 , 0}$ \\
\hline
\end{tabular}

Fonte: Instrumento de Pesquisa PIBIC, 2014. 
De acordo com os dados expostos, nota-se que $\mathbf{R} 7$, $\mathbf{R} \mathbf{9}$ e $\mathbf{R} \mathbf{2}$ apresentaram o maior número de ações realizadas nesse período, abrangendo 19\%, 15,5\% e 13,1\%, respectivamente, totalizando 47,6\% das ações realizadas no Estado. Em relação à carga horária, R7, R9 e R5 se destacam nesse quesito, totalizando $88,7 \%$ da carga horária das ações de EPS em SC. No que se referem aos participantes dessas ações, $\mathbf{R 2}, \mathbf{R} \mathbf{3}$ e $\mathbf{R} \mathbf{7}$ totalizam 6.444 participantes capacitados, representando $61 \%$ dos participantes de todas as regiões. Assim, a $\mathbf{R} \mathbf{7}$ destaca-se como uma região expressiva no que condiz à quantidade de ações de EPS.

Frente aos dados expostos, Lino et. al (2009) esclarecem que o desenvolvimento das ações de EPS é influenciado por fatores de ordens dinâmicas e coletivas, singulares de cada região, envolvendo vários aspectos, como o conhecimento experiências vivenciadas anteriormente pelos atores responsáveis pelo processo de EPS, número de profissionais envolvidos, além da adequação filosófica do serviço à metodologia educativa e aos aspectos culturais.

Neste contex to, também se insere a questão da valorização da criação de compromissos entre as diferentes redes de gestão, de serviços de saúde, educação e de controle social, promovendo um enfrentamento dinâmico dos problemas e uma maior efetividade das ações de EPS, assim o quadrilátero figura-se como um mobilizador de mudanças e caminhos (MENESES, 2012).

A Tabela 02 apresenta dados relativos ao total de ações promovidas no estado destinadas aos segmentos gestão, ensino, serviço e controle social no período de 2011 a 2013.

Tabela 02- Distribuição de ações de EPS realizadas para os segmentos do quadrilátero (2011-2013), 2014

\begin{tabular}{|c|c|c|c|c|c|c|}
\hline \multirow{2}{*}{ Quadrilátero } & \multicolumn{2}{|c|}{ Ações } & \multicolumn{2}{|c|}{ Carga Horária } & \multicolumn{2}{|c|}{ Participantes } \\
\hline & & $\%$ & $\mathrm{~N}$ & $\%$ & $\mathrm{~N}$ & $\%$ \\
\hline Gestão & 27 & 32,1 & 632 & 05,2 & 3441 & 32,5 \\
\hline Ensino & 14 & 16,7 & 9401 & 76,9 & 1057 & 10,0 \\
\hline Serviço & 40 & 47,6 & 2058 & 16,9 & 5720 & 54,1 \\
\hline Controle Social & 03 & 03,6 & 128 & 01,0 & 356 & 03,4 \\
\hline Total & 84 & 100 & 12219 & 100 & 10574 & 100 \\
\hline
\end{tabular}

Fonte: Instrumento de Pesquisa PIBIC, 2014.

O segmento serviço representou 47,6\% das ações, com de 54,1\% de participantes, seguido do segmento gestão com $32,1 \%$ das ações e $32,5 \%$ de participação nas ações. O segmento ensino destaca-se com 76,9\% da carga horária total das ações de EPS. Houve poucas ações destinadas ao segmento controle social, com apenas 03,6\% das ações, 01,0\% da carga horária e 03,4\% de participação.

Meneses (2012) reitera que se deve buscar a ampliação dos seguimentos do quadrilátero, de forma a integrar a qualidade da atenção integral à saúde, partilhando os saberes na produção do cuidado no âmbito individual e coletivo, potencializando o exercício da cidadania.

A Tabela 03 representa o envolvimento do quadrilátero na realização e na execução das ações de EPS no estado por região. Ressalta-se que mais que um segmento pode estar envolvido na realização de uma única ação de EPS. Assim, o segmento Gestão destaca-se por estar envolvido em 56 de um total de 84 ações de EPS; enquanto que o Controle Social minimamente esteve envolvido, concentrando-se em apenas 11 ações do total. 
22 - RBTS - v.1, n.2, 2014

Tabela 3- Distribuição dos segmentos do quadrilátero envolvidos na realização das EPS promovidas em SC, por região (2011-2013), 2014

\begin{tabular}{lcccccccc}
\hline Quadrilátero & \multicolumn{2}{c}{ Gestão } & \multicolumn{2}{c}{ Ensino } & \multicolumn{2}{c}{ Serviço } & \multicolumn{2}{c}{ Controle Social } \\
Região & $\mathrm{N}$ & $\%$ & $\mathrm{~N}$ & $\%$ & $\mathrm{~N}$ & $\%$ & $\mathrm{~N}$ & $\%$ \\
\hline R1 & 05 & 08,9 & 05 & 11,9 & 01 & 02,2 & 00 & 00,0 \\
R2 & 11 & 19,6 & 10 & 23,8 & 11 & 24,4 & 09 & 81,8 \\
R3 & 07 & 12,5 & 00 & 00,0 & 09 & 20,0 & 00 & 00,0 \\
R4 & 02 & 03,6 & 06 & 14,3 & 00 & 00,0 & 00 & 00,0 \\
R5 & 04 & 07,2 & 04 & 09,5 & 00 & 00,0 & 00 & 00,0 \\
R6 & 00 & 00,0 & 02 & 04,8 & 00 & 00,0 & 00 & 00,0 \\
R7 & 11 & 19,6 & 00 & 0,0 & 16 & 35,6 & 01 & 09,1 \\
R8 & 04 & 07,2 & 01 & 02,4 & 01 & 02,2 & 01 & 09,1 \\
R9 & 05 & 08,9 & 10 & 23,8 & 00 & 00,0 & 00 & 00,0 \\
R10 & 07 & 12,5 & 04 & 09,5 & 07 & 15,6 & 00 & 00,0 \\
\hline Total & $\mathbf{5 6}$ & $\mathbf{1 0 0 , 0}$ & 42 & 100,0 & 45 & 100,0 & 11 & 100,0 \\
\hline
\end{tabular}

Fonte: Instrumento de Pesquisa PIBIC, 2014.

O segmento Gestão figura-se de forma expressiva no envolvimento da realização de EPS em R2 e R7, com 19,6\% cada, e R3 e R10 com 12,5\% ambos. O segmento Ensino esteve envolvido em 23,8\% na realização das ações em $\mathbf{R} 2$ e $\mathbf{R 9}$; em $\mathbf{R} 4,14,3 \%$, totalizando 61,9\% de representação em SC. O segmento Serviço aparece com representatividade em R7, R2 e R3, com 35,6\%, 24,4\% e 20,0\% respectivamente, totalizando $80 \%$ no envolvimento das ações de EPS no estado. O segmento Controle Social limitou-se a R2, com $81,8 \%$ de envolvimento.

A interação entre os segmentos ensino, serviço, gestão e controle social na condução da EPS deve desenvolver as potencialidades existentes em cada realidade, valorizando as habilidades instaladas, estabelecendo um processo de aprendizagem significativa e efetiva, também mantendo uma capacidade crítica, de autoanálise e autogestão (CECCIM, 2005).

Ceccim e Feuerwerker (2004, apud SARRETA; BERTANI, 2009) reforçam que a participação e a boa articulação do "quadrilátero da formação" na propagação da EPS e da sua integração entre os diversos setores que determinam o processo de trabalho constituem uma experiência inovadora que busca como resultado a aproximação da formação dos trabalhadores com as reais necessidades dos serviços de saúde, trazendo assim, como referência, as necessidades de saúde tanto dos usuários como dos trabalhadores.

Os profissionais que se comprometem com a educação permanente em saúde contribuem agregando qualidade na prestação dos serviços para a resolutividade, satisfação dos usuários e integração com a comunidade, estimulando a autonomia e o autocuidado, pois contribuem para atualização de conhecimentos, como forma de crescimento pessoal, de qualificação, que auxilia na prevenção e n correção de erros e mudanças de atitudes (PAULINO; SOUZA; BORGES, 2010).

A Figura 02 demonstra a participação das categorias profissionais nas ações de EPS. Entende-se que a participação nestas ações está relacionada com temáticas predefinidas, a fim de atingir determinado público-alvo, de forma que a participação destas categorias esta ligada à necessidade de profissionais capacitados para suprir a necessidade que levou à criação de determinada EPS. 
Figura 2. Distribuição da participação das categorias profissionais nas ações de EPS no estado de SC (2011 $-2013), 2014$

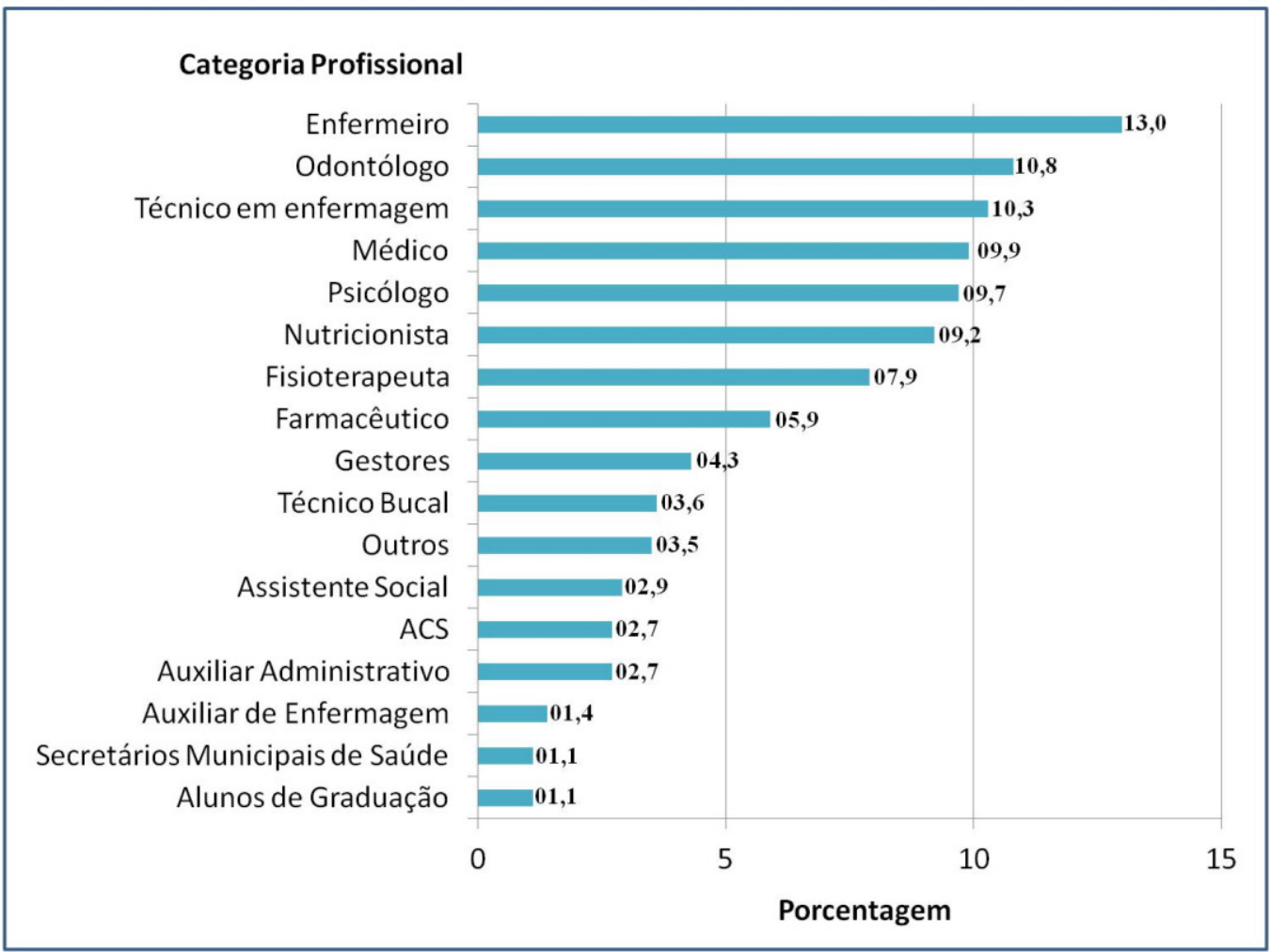

Fonte: Instrumento de Pesquisa PIBIC, 2014.

O profissional Enfermeiro ganha destaque nestas ações, com 13\% de participação em detrimento a outras categorias. Os técnicos de Enfermagem representaram 10,3\%, enquanto os auxiliares de Enfermagem, 1,4\%, de forma que juntamente com o Enfermeiro, a equipe de Enfermagem totaliza 24,7\% de participação. Os dados do Conselho Federal de Enfermagem (COFEN) nos mostram que, no mês de março do ano de 2010 , existiam 1.449 .583 profissionais registrados, sendo 19,8\% de enfermeiros, $43,2 \%$ de técnicos de enfermagem e $36,8 \%$ de auxiliares de enfermagem e é a região Sudeste que detém de $52,4 \%$ da força de trabalho de enfermagem. No ano de 2001, o Brasil possuía 3,41 profissionais de enfermagem por 1000 habitantes, já no ano de 2010 verificou-se o equivalente a 7,76/1000 hab. (MACHADO; VIEIRA; OLIVEIRA, 2012).

Este fato demonstra que o enfermeiro, na essência de sua profissão, tem na educação permanente um requisito para o exercício da prática profissional comprometida com as reais necessidades de saúde da população. De acordo com o Decreto 94.406, de 8 de junho de 1987, que regulamenta o exercício da enfermagem, especifica-se que ao enfermeiro incumbe, como integrante da equipe de saúde, a "participação nos programas de treinamento e aprimoramento de pessoal de saúde"; cenário este verificado nas ações de EP levantadas no estado. Infere-se ainda que o enfermeiro, além do direito de manter-se atualizado, possui o dever de participar como educador dos demais profissionais de enfermagem (PASCHOAL, 2004, p. 22).

Os profissionais de Odontologia (10,8\%), Medicina (9,9\%), Psicologia (9,7\%), Nutrição (9,2\%), Fisioterapia (7,9\%), Farmácia (5,9\%) e Assistência Social (2,9\%) totalizam 56,3\% de participação. Pode-se inferir que estes profissionais possuem esta representatividade, pois 
grande parte das ações de EPS realizadas busca suprir deficits de conhecimento na atenção básica nestas disciplinas.

As ações de EPS para a equipe multiprofissional trazem contribuições para a consolidação da atenção básica e, consequentemente, para o SUS, estimulando o aperfeiçoamento, a atualização e a qualificação dos trabalhadores para trabalhar com a comunidade. Os profissionais são vistos como protagonistas nestas ações, viabilizando uma maior integração da equipe no processo de ensino-aprendizagem (PAULINO; SOUZA; BORGES, 2010).

A categoria "Outros" consiste na soma das categorias profissionais que atingiram menos de 0,5\% de participação, sendo estas: Biólogo, Profissional de Nível Técnico, Auxiliar de Serviços Gerais, Digitador, Conselheiro Municipal, Profissional da Educação, Agente de Endemias, Técnico em Saúde, Recepcionista e Motorista.

A política de educação permanente em saúde preconiza que representantes dos segmentos de ensino, serviço, gestão e controle social vivenciem ativamente o processo de construção e efetivação da política. Assim, é fundamental que os membros da CIES conheçam o processo de gestão, organização e estruturação da política, descentralização da gestão pública e responsabilização pelo planejamento e execução das ações de EPS (FERRAZ et al. 2013).

\section{CONSIDERAÇÕES FINAIS}

Em Santa Catarina todos os municípios estão integrados a uma CIES e esta a CIR. Conforme a Portaria 1.996/O7, a CIR é a responsável pela condução da PEPS na região e a CIB no âmbito estadual, já as CIES correspondem à comissão de apoio dessas instâncias deliberativas, contudo fazem mais do que apoiar, elas são as que realizam de fato a PEPS, mas com o aval da CIR. Portanto, é por meio das CIES que é possível mapear as ações desenvolvidas no Estado.

Neste estudo, não se conseguiu obter informações de duas CIES dentre as 16 CIES existentes no Estado, embora se tenha solicitado por diversas vezes, contudo, por ser voluntária a participação, não há como exigir, sendo assim os resultados alcançados correspondem à maioria das CIES e não à sua totalidade.

As ações de EPS desenvolvidas em Santa Catarina seguem o que preconiza a Portaria 1996/07. É realizado o diagnóstico das necessidades regionais de educação permanente e este é planejado de acordo com a área temática juntamente com a especificação a quem se destina; após é apresentada a CIR, que faz a homologação (ou não) das ações, podendo haver remanejamento. Salienta-se que todas as atividades de educação permanente, inclusive as de formação técnica, são aprovadas pela CIR, as quais ficam registradas em ata da CIR.

Identificou-se que as CIES regionais têm reuniões ordinárias e cada qual segue uma cronologia diferenciada, dependendo da necessidade regional. O processo de desenvolvimento da EPS no Estado de Santa Catarina orienta seu planejamento de acordo com o reconhecimento das CIES regional. A aproximação entre o cotidiano dos profissionais de saúde e o contexto sociocultural dos usuários faz com que aconteça a instrumentalização da construção e a reorganização do SUS.

A EPS relaciona diretamente com os processos de trabalho e tem o profissional como sujeito ativo na ação de transformação do seu trabalho vivo a partir da problematização das suas necessidades. Há muito o que aprender neste ato de construir e desconstruir ideias e atitudes profissionais herméticas frente ao mundo contemporâneo dinâmico de trabalho que se desponta. 


\section{REFERÊNCIAS}

BRASIL, Ministério da Saúde (MS). Secretaria de Gestão do Trabalho e da Educação na Saúde (SGTES). Departamento de Gestão da Educação na Saúde (Deges). Política de Educação e Desenvolvimento para o SUS: caminhos para a educação permanente em saúde - Pólos de educação permanente em saúde. Brasília: Ministério da Saúde, 2004a, 66p. (Série C. Projetos, Programas e Relatórios).

Ministério da Saúde. Portaria GM/MS nº 198, de 13 de fevereiro de 2004. Institui a Política

Nacional de Educação Permanente em Saúde como estratégia do Sistema Único de Saúde para a formação e o desenvolvimento de trabalhadores para o setor e dá outras providências. Brasília, DF; 2004b.

Conselho Nacional de Secretarias de Saúde. Seminário do CONASS: Para entender o pacto pela saúde. Brasília: Ministério da Saúde, 2006.

Ministério da Saúde. Portaria GM/MS n 1.996, de 20 de agosto de 2007. Dispõe sobre as diretrizes para a implementação da Política Nacional de Educação Permanente em Saúde e dá outras providências. Brasília, DF: Ministério da Saúde; 2007.

FERRAZ, F. et al. Gestão de recursos financeiros da educação permanente em saúde: desafio das comissões de integração ensino serviço. Revista Ciência e Saúde Coletiva. Rio de Janeiro, v.18, n.6, 2013.

LINO, M. M. et al. Educação permanente dos serviços públicos de saúde de Florianópolis, Santa Catarina. Trab. Educ. Saúde, Rio de Janeiro, v. 7, n. 1, p.115-136, 2009.

MACHADO, M. H.; VIEIRA, A. L. S.; OLIVEIRA, E. Construindo o perfil da enfermagem. Enfermagem em Foco, São Paulo, v. 03, n. 03, p.119-122, jul. 2012.

MENESES, M. N. A Política Nacional de Educação Permanente nas unidades básicas de pronto atendimento do município do Rio Grande, RS: dificuldades e facilidades. 2012. 38 f. Dissertação (Mestrado) - Curso de Especialização em Gestão em Saúde EAD, Universidade Federal do Rio Grande do Sul, Porto Alegre, 2012.

MERHY, E. E.; FEUERWERKER L.C.M.; CECCIM R.B. Educación Permanente en Salud: una estrategia para intervenir en la micropolítica del trabajo en salud. Salud Coletiva, Buenos Aires, v.2, n. 2, p. 147-160, 2006.

PASCHOAL, A. S. O discurso do enfermeiro sobre educação permanente no grupo focal. $2004.113 \mathrm{f}$. Dissertação (Mestrado) - Curso de Enfermagem, Universidade Federal do Paraná, Curitiba, 2004.

PAULINO, V. C. P.; SOUZA, P. R. de; BORGES, C. J. Contribuições da Educação Permanente em serviço no contexto da estratégia de saúde da família. Itinerarius Reflectionis, Jataí, v. 2, n. 9, p.1-11, 2010.

SARRETA, F. O.; BERTANI, I. F.. Perspectivas da Educação Permanente em Saúde. Revista Iberoamericana de Estudos em Educação, Araraquara, v. 4, n. 3, 2009.

SAUPE, R.; CUTULO, L.R.A.; SANDRI, J.V.A. Construção de descritores para o processo de educação permanente em atenção básica. Trabalho Educação e Saúde, Florianópolis, v. 5, n. 3, p. 433-52, 2008. 